\title{
Assessment Of Psychological Factors Associated With Chronic Pain Patients.
}

\author{
Prof. Agashua, Atume Philemon ${ }^{1}$, Dr. Chia, Perpetua Ngosoo ${ }^{2}$, \\ Ugese, Jonathan Iornenge $^{3}$, Dr. Abamara, Nnaemeka Chukwudum ${ }^{4 *}$ \\ ${ }^{I}$ Department of Psychology Nigerian Defense Academy (NDA) Kaduna, Nigeria. \\ ${ }^{2 \& 3}$ Department of Clinical Psychology, Federal Medical Centre, Makurdi, Nigeria. \\ ${ }^{4}$ Department of Psychology, Nnamdi Azikiwe University, Awka, Nigeria.
}

\begin{abstract}
This study assessed psychological factors associated with chronic pain patients at Federal Medical Centre, Makurdi, Nigeria. The study was a cross-sectional survey where 195 patients (118 males and 77 females) were selected for the study through a simple random sampling method. Their ages ranged from $17-$ 64 years with the mean of (28). Self-Rating Depression Scale (SDS), State Trait Anxiety Inventory (STAI) Form Y-1 and Big Five Inventory (BFI) were used for data collection. Data were analyzed using Pearson ProductMoment correlation coefficient to establish the relationship between personality and pain and independent $t$ test to test the differences between the groups. The results showed a significant difference in depression between male and female patients experiencing pain $(t d f(193)=2.37 ; p<.05)$. No significant difference was however observed between medical and surgical patients on anxiety $(t d f(193)=-.42, p>.05)$. Also, there was a significant negative relationship between Open personality trait and pain $(r d f(143)=-.16, p<.05)$. Based on these findings, it was recommended that Psychologists should be included in the treatment team for the effective management of chronic pain and that further research in the study area should be conducted using larger sample.
\end{abstract}

Key Words: Depression, Anxiety, Extraversion, Agreeableness, Conscientiousness, Neuroticism, Openness and Chronic Pain.

\section{Introduction}

Pain is an unpleasant sensory and emotional experience usually produced by something that injures; or threatens to injure the body. Pain begins with a stimulus, but is influenced by physiological and psychological factors before it becomes part of our consciousness (Howard, 2007). From a clinical perspective, pain has been categorized into four types according to Sternberg (2004): acute, chronic, non-receptive and neuropathic. While acute pain is usually associated with tissue damage, chronic pain is a result of complex systems. It is better understood as the integration of biomedical and physiological processes. Psychological factors play an important role in sustaining pain perception and coping. Furthermore, pain has been categorized by Sternberg (2004) as Organic pain and psychogenic pain, acute pain and chronic pain. Acute Pain is a brief, intense, uncomfortable stimulation usually associated with internal or external tissue damage. While Chronic Pain is a recurrent or constant long-term discomfort, usually associated with tissue damage, and lasting at least 6 months. In addition, Organic pain is the kind of pain that is characterized by sensations of extreme discomfort and suffering caused by damage to bodily tissue. Psychogenic Pain on the other hand is an intense sensory emotional suffering for which Physiological origins cannot be found.

Perhaps, pain is something that we invariably want to escape or to stop, it serves very important functions. It protects us by triggering a reflexive withdrawal from something damaging before we can suffer further injury. It is also a warning system that lets us know when an injury is about to occur. Pain forces us to immobilize or protect an injured part, such as a broken ankle, thus giving it a chance to heal. Pain also lets us know when we need to seek medical help, and teaches us what behaviors to avoid in the future. For this reason, Sternberg (2004) noted that our perceptions of pain interact with our cognitions regarding it. Based on our experiences, we form schemas about pain as well as beliefs about our ability to control it.

Nevertheless, patients often experience a significant decrease in perceived control over their lives and circumstances when they are in severe pain. During this turbulent period, it appears that the individual's entire world-view, as well as his or her plans and hopes for the future, are suddenly thrown into question. Depression, anxiety, and somatizing of emotional distress may be strongly related to this overall belief that one has completely lost control over his or her life as a result of the pain and the individual begins to have intense feeling of psychological pain, tendency to commit suicide, manifestation of depression and hostility (Holden, Metha \& Cunningham, 2001). In association with the above, the individual also presents feelings of shame, guilt, humiliation, loneliness, fear, anger, dread and anguish. It is in line with the above psychological expression of pain that this study is conducted. 
Chronic pain is a major public health problem that places serious stress on afflicted individuals, the health care system and private industry. It has been associated with deficits in quality of life, psychological adjustment, disability, reduced income potential, high levels of health care utilization and high costs to private industry. Generally defined as any continuous or persistent intermittent pain experienced for a period longer than three months (Merskey \& Bogduk, 1994). Chronic pain affects individuals of all ages and ethnic backgrounds as well as both sexes. However, epidemiological, clinical and experimental studies have all consistently found that the burden of pain is greater for women than for men. The magnitude of the sex difference in pain is difficult to determine, as it varies, depending on the type of pain and the population being studied (Leresche, 1998; Fillingim, 2000). Recent reviews, however, report that the prevalence of most pain conditions is higher among women than men (Unruh, 1996; Berkley, 1997). Identifying the sources of this difference in pain is a complex matter that requires a bio-psychosocial perspective.

Chronic pain leads to a vicious cycle of depression, helplessness, guilt, and increased preoccupation with pain. It is accompanied by a multitude of negative behavioural responses like restricted activity, sleep deprivation, and social withdrawal. Misuse of opioid, analgesics and alcohol complicate patients' problematic behaviours. Patients with chronic pain often resist referral to mental health professionals. By the time they present to mental health services, many have already seen a number of physicians, some of whom may have implied that the pain is purely psychogenic. It can be challenging to establish a therapeutic alliance with patients who respond with defensiveness or hostility.

Psychological factors play an important role in sustaining pain perception and coping.Nevertheless; patients often experience a significant decrease in perceived control over their lives and circumstances when they are in severe pain. During this turbulent period, it appears that the individual's entire world-view, as well as his or her plans and hopes for the future, are suddenly thrown into question. Depression, anxiety, and somatizing of emotional distress may be strongly related to this overall belief that one has completely lost control over his or her life as a result of the pain and the individual begins to have intense feeling of psychological pain, tendency to commit suicide, manifestation of depression and hostility (Holden, Metha \& Cunningham, 2001).

Studies conducted have shown that psychopathology affects between $30 \%$ and $50 \%$ of patients seen in academic and community pain centers with depression, anxiety, personality disorders and substance abuse being the primary diagnoses (Fishbain, 1999; Wasan, 2004). The role of the patient's personality as a predictive variable in the coping process and its effect on the patient's adjustment to this stressful situation is further investigated. Several authors have defended the role of personality as an antecedent variable influencing how people adjust to stressful situations (Ramírez-Maestre, López, \& Esteve, 2004). They argue that personality is a determinant in the coping strategies people use in stressful situations and that these strategies are responsible for good or poor adjustment. Most research has analyzed the influence of the dimensions of Neuroticism, Extraversion and Dispositional Optimism as antecedent variables in this process. The results of several studies on chronic pain support this relationship. Some studies show a relationship between the neuroticism dimension and poor adjustment (Asghari, 1997). Other works have reported a relationship between the extraversion dimension and lower intensity of perceived pain and less subjective discomfort (Morasso, Costantini, Baracco, Borreani, \& Capelli, 1996).

The experience of pain and the threat of pain can lead to negative or low affect. Chronic low affect, including persistent feelings of frustration and anger; and negative or destructive self appraisal are common effects of persistent pain. Unsurprisingly, the majority of adult chronic pain patients who present for treatment at pain clinics are also depressed to some degree. However, this depression is not brought about directly by the pain severity but by the disabling consequences of how one reacts to the chronic pain (Turk, Okifuji, \& Scharff, 1995).

\section{Design of the Study}

This study employed a Cross-sectional survey design to assess the psychological factors of patient's about their pain at Federal Medical Centre, Makurdi. This design was employed because the researcher did not intend to manipulate the variables but simply investigate the differences and relationship that exist between variables.

\section{Research Hypotheses}

The following hypotheses were stated and tested in the course of the study.

(i) There will be a significant difference in depression between male and female patients experiencing pain.

(ii) There will be a significant difference in the anxiety state of medical and surgical patients experiencing pain. 
(iii) There would be a positive relationship between personality traits and the experience of pain among patients

\section{Participants}

Samples of one hundred and ninety five (195) patients were selected from Federal Medical Centre, Makurdi for the study. $118(60.5 \%)$ were males and $77(39.5 \%)$ were females. The age range of the participants was from 17 to 64 with a mean age of 28 years.

Furthermore, a total of $98(50.3 \%)$ patients were sampled from A-Male medical ward, $44(22.6 \%)$ were from B-Female medical ward, $21(10.8 \%)$ were from Male surgical/orthopedic ward while $32(16.4 \%)$ were from Female surgical/orthopedic ward. A total of $53(27.2 \%)$ participants were civil servants, $56(28.7 \%)$ were students, $16(8.2 \%)$ were farmers, $8(4.1 \%)$ were engineers, $45(23.1 \%)$ were youth corp members and 17 $(8.7 \%)$ represents other groups.

In the sampled population, $163(83.6 \%)$ patients were Christians, 29 (14.9\%) were Muslims and 2 (1\%) represents other religion. The marital status of the participants shows that $98(50.3 \%)$ were single, 85 $(43.6 \%)$ were married, $8(4.1 \%)$ were widowed and $4(2.1 \%)$ were separated/divorced.

Again, $24(12.3 \%)$ of the patients had FSLC, 76 (39\%) had WASCE/SSCE/TCII, 45 (23.1\%) had ND/NCE, $49(25.1 \%)$ had Degrees/HND, while 1(.5\%) had Masters Degree. A total of $92(47.2 \%)$ patients were within low socioeconomic status, $93(47.7 \%)$ were within medium socioeconomic status, $9(4.6 \%)$ fall within higher socioeconomic status.

\section{Sampling Technique}

A simple random sampling technique was used to select patients for the study. A randomization of every second $\left(2^{\text {nd }}\right)$ patient out of the total number of patients in each ward was selected to participate in the study. This gave each participant equal chance of participating in the study without bias selection.

\section{Instruments}

The main instrument used in this study was the questionnaire put together by the researchers with four sub-scales. The first part (section A) of the questionnaire sought information on participants' demographic characteristics. The second part of the questionnaire consists of three standardized psychological tests thus:

The Self-Rating Depression Scale (SDS); developed by William (1965) to measure depression. It has 20 items with four responses ranging from "some or a little of the time (1), some of the time (2), Good part of the time (3) and Most or all of the time (4). Obiora (1995) obtained a three day interval reliability coefficient of .93 and Zung (1965) obtained concurrent validity of .79. In the present study, the scale yielded a reliability coefficient alpha of 0.70 for its internal consistency. This scale formed section B of the instrument.

State-Trait Anxiety Inventory (STAI) Form Y-1; developed by Spielberger (1983) to measure state anxiety which is a situation-specific emotion characterized by feelings of tension, apprehension and autonomic arousal. Spielberger (1983) provided a test-retest reliability of .61 for Nigerian sample. In the present study, the scale yielded a reliability coefficient alpha of 0.71 for its internal consistency. This scale formed section $\mathrm{C}$ of the instrument.

Big Five Inventory; developed by John, Donahue and Kentle (1991) to measure Personality on five subscales; that is extraversion, agreeableness, conscientiousness, neuroticism and openness. It consists of 44 items. John $e t$ al.(1991) provided the Cronbach Alpha Coefficients of .80 and 3 months test-Retest reliability coefficient of .85, while Costa and Mc Crae (1992), Golberg (1992) provided Mean Convergent Validity Coefficients of .75 and .85 respectively; and Umeh, (2004) provided a Divergent Validity Coefficients as follows:- Extraversion .05 , Agreeableness .13, Conscientiousness .11, Neuroticism .39 and Openness .24. In the present study, the scale yielded a reliability coefficient alpha of 0.77 for its internal consistency. This scale formed section D of the research instrument.

Pain; As for Pain, no standardized scale was used but the researchers requested from each of the patients to indicate the severity of their pain on a three point Likert Scale beginning from "Low, Moderate and severe" by ticking which one out of these three responses apply to them.

\section{Procedures}

The researchers employed the assistance of clinical psychologists who were posted in the wards to assist in the collection of the data. After establishing rapport with the participants and seeking for their consent, the questionnaires were then administered to them. For the literate participants, the questionnaire was given to them to respond appropriately. While non-literate participants were assisted by the clinical psychologists. The questionnaires were collected after the patients completed responding to it. There was no time limit for the patients to respond to the questionnaire. 


\section{Method of Data Analysis}

Descriptive statistics such as means, standard deviations and percentages were used to describe the demographic characteristics of patients. While inferential statistics such as Independent samples t-test and Pearson Product-Moment Correlation Statistics were used to test the research hypotheses.

\section{Results}

The hypotheses formulated in the study were analyzed and the results presented as thus:

The first hypothesis stated that, there will be a significant difference in depression between male and female patients experiencing pain was tested using the independent $t$-test.

Table 1: Summary of Independent sample t-test showing difference in the Depression between male and female patients experiencing pain.

\begin{tabular}{lcccccccc}
\hline $\begin{array}{l}\text { Variable } \\
\text { Remarks }\end{array}$ & & $\mathbf{N}$ & $\mathbf{X}$ & SD & df & t & $\alpha$ & \\
\hline \multirow{2}{*}{$\begin{array}{l}\text { Mepression } \\
\end{array}$} & 118 & 50.39 & 9.08 & & 193 & 2.37 & $<.05$ & Sig \\
& Female & 77 & 47.47 & 7.28 & & & & \\
\hline
\end{tabular}

The result of Independent sample t-test presented in table 1 showed a significant difference in depression between male patients and female patients experiencing pain. The hypothesis was therefore confirmed ( $\mathrm{df}$ $(193)=2.37 ; p<.05)$.

The result further shows that the mean scores $(X=50.39)$ of the male participants on depression was higher than the mean score $(X=47.47)$ of the female participants. This finding implies that males were more depressed than females in experiencing pain.

Hypothesis 2 which stated that, there will be a significant difference in the anxiety state of medical and surgical patients experiencing pain was tested using the independent t-test.

Table 2: Summary of Independent sample t-test showing the difference in the Anxiety state between medical and surgical patients experiencing pain.

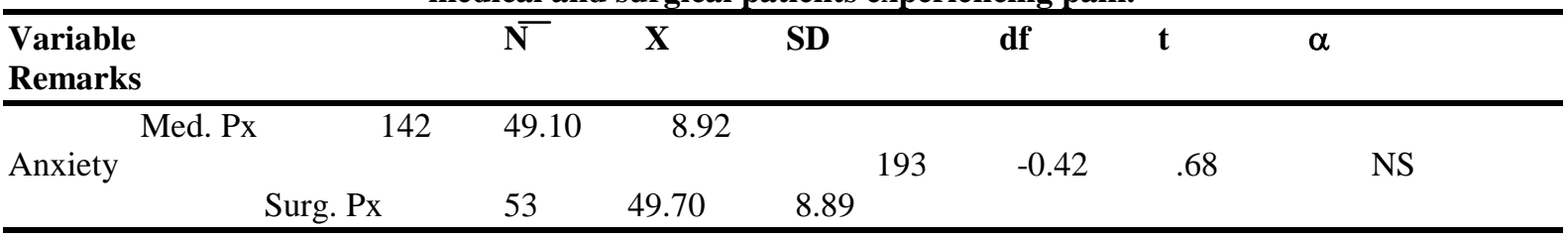

The result of the Independent t-test presented in table 2 shows that there is no significant difference in the anxiety state between medical and surgical patients experiencing pain, the hypothesis is therefore not confirmed (t df $(193)=-.42 ; p>.05)$. Also, the mean scores of the medical patients $(\mathrm{X}=49.10)$ was not significantly different from the mean scores of the surgical patients $(X=49.70)$. This finding therefore implied that the anxiety experienced by medical and surgical patients during pain does not differ significantly.

Hypothesis 3 which stated that, there would be a positive relationship between personality traits and the experience of pain among patients were tested using the Pearson Product-Moment correlation.

Table 3: Summary of Pearson Product-Moment correlation showing the relationship between personality traits and pain.

\begin{tabular}{lccccc}
\hline Variables & N & r & df & $\alpha$ & Remarks \\
\hline Extraversion & 195 & -0.08 & 194 & .25 & NS \\
Pain & 195 & -0.00 & 194 & .96 & NS \\
\hline Agreeableness & & & & & \\
Pain & 195 & -0.05 & 194 & .46 & NS \\
\hline Conscientiousness & & & &
\end{tabular}

Neuroticism 
Assessment Of Psychological Factors Associated With Chronic Pain Patients.

\begin{tabular}{llllll}
\hline & 195 & -0.03 & 194 & .69 & NS \\
Pain & 195 & -0.16 & 194 & .03 & Sig \\
\hline Openness & & & & \\
\hline
\end{tabular}

The result of Pearson correlation presented in table 3 shows that there is no significant relationship between extraversion and pain $(\mathrm{r}$ df $(194)=-0.08 ; p>.05)$. This implied that extraversion has no relationship with patients' experience of pain

There is no significant relationship between agreeableness and pain $(\mathrm{r} \operatorname{df}(194)=-0.00 ; p>.05)$. Implying that agreeableness has nothing to do with the experience of pain.

There is no significant relationship between conscientiousness and pain ( $\mathrm{r}$ df $(194)=-0.05 ; p>.05)$. This result here also signifies that conscientiousness has nothing to do with the experience of pain.

Similarly, there is no significant relationship between Neuroticism and pain ( $\mathrm{r}$ df $(194)=-0.03 ; p>$ .05). Implying that Neurotic/ highly emotional personality has no relationship with the experience of pain by patients.

Finally, result presented in table 3 shows a significant negative relationship between openness and pain ( $r$ df $(194)=-0.16 ; p<.05)$. In this result, the researcher discovered that there is a negative relationship that exists between openness personality trait and pain.

\section{Discussion}

The first hypothesis stated that there will be a significant difference in depression between male and female patients experiencing pain was confirmed. This finding support previous studies which have shown that Psychological distress is common in both men and women who experience chronic pain, depression being a common, strong correlate (Meana \& Stewart, 2000). Findings from population-based studies also indicate that the prevalence rates of depression are higher in women (Murrell, Himmelfarb and Wright 1983; Ensel, 1986); this is in contrast with the findings of this study which shows that males experience more depression $(\mathrm{X}=$ 50.39) than females $(X=47.47)$. However, these findings need to be placed within the context that women are more likely to express their feelings and report more symptoms than men (Verbrugge, 1985).

The second hypothesis which stated that, there will be a significant difference in the anxiety state of medical and surgical patients experiencing pain was not confirmed. This finding supported the study of Cavanaugh (1983) who reported that both medical and surgical patients undergo a variety of stressful experiences. In addition to the stress of physical illness, hospitalized patients often lose work, independence, body image, and social identity. Patients also may face invasive testing and the possibility of an uncertain diagnosis, an incurable disease, or even death can make most patients present anxiety along side with the physical symptoms of their illness.

The third hypothesis which stated that, there would be a significant relationship between personality traits (Extraversion, Agreeableness, Conscientiousness and Neuroticism) and the experience of pain among patients was not confirmed. However, result further shows a significant relationship between open personality trait and pain. This finding is in line with Ashton, Ebenezer and Golding (1984); Davidson and McDougall (1969). Levine, Tursky and Nichols (1966) and Schalling (1971) all reported no significant correlation between personality and pain, Furthermore, Taenzer, Melzack and Jeans (1986) also found no correlation between personality dimensions and post-operative gallbladder pain.

Lynn and Eysenck (1961) however found higher pain tolerance among extroverted subjects, whereas Martin \& Inglis, (1965) and Brown, Fader and Barber (1973) using the cold pain model failed to report a significant relationship between personality and pain. As for clinical pain, Bond, Glynn and Thomas (1976) found higher pain magnitude among extroverted patients suffering from back surgery pain.

LePine, LePine and Jackson (2004) found a negative association between conscientiousness and emotional pain. However, Piedmont (1993), Deary, Blenkin, Agius, Endler, Zealley and Wood (1996), and Deary, Watson and Hogston (2003) all found a positive relationship between conscientiousness and pain. Again, Deary, et al., (2003) in their longitudinal analysis of pain in nursing students indicated a positive relationship between conscientiousness and pain.

Buhler and Land (2003) found that individuals who were higher in neuroticism experienced the highest level of pain. Similarly, Zellars, Perrewe and Hochwarter (2000) carried out a study on the relationship between neuroticism and pain and they found that individuals who are high in neuroticism are more likely to report feelings of emotional exhaustion and lower levels of personal achievement.

Zellars, et al., (2000) reported a positive relationship between openness and pain and in addition found a negative relationship between openness and pain; this is similar to findings of this study which established a negative relationship between openness and pain. McCrae \& Costa, (1986) in their study found that openness is 
related to the use of humor as a way of dealing with stress or pain. Deary, Blenkin, Agius, Endler, Zealley and Wood (1996) in their studies established a modest, but significant positive relationship between openness and pain.

\section{Recommendations}

Based on the findings in this study, the researchers therefore recommended that;

1) Clinical Psychologists should be employed in all hospitals so that they take charge of the psychological assessment of patients.

2) Psychological Assessment of pain for all patients admitted in the hospital with varied kind of medical problems should be incorporated as part of investigations even if the primary reason of the patient's visit to the hospital was for medical purpose only.

3) Cognitive behavioral strategies such as reframing or restructuring the negative self-talk (Thoughts) have been proven to be beneficial in helping patients with pain to regain a sense of perceived control. The Psychologists are therefore encouraged to assist patients with pain to become more aware of how thoughts create feelings and by teaching the patients that distressful emotions, such as depression and anxiety, exacerbate perceptions of pain.

4) Psychologists, Doctors and Nurses should provide patients with information and reassurance to calm those fears and prepare the patient's mind before and after he or she is taken to the theatre for surgery.

5) Further research should be conducted to assess the personality profiles of patients. Such studies would help the Psychologists, Doctors and Nurses to know more about the personality of the patients and how it relates to pain in order to help improve the quality of life and care of patients.

\section{Conclusion}

Pain is a major public health problem that places serious stress on afflicted individuals, the health care system and private industry. It has been associated with deficits in quality of life and psychological maladjustment. Major findings in the present study therefore have important implications. The role of psychological factors in the systemic hyper responsiveness to pain has demonstrated more severe complexity of the disorder. For this reason, the researchers hereby recommends that psychological assessment of patients who present with painful coitus should include not only a medical examination but also psychological evaluation of pain and personality characteristics. Such a process will facilitate the emergence of a more-comprehensive understanding of patient profiles and management.

\section{References}

[1]. Asghari, M. A. (1997). The relative contribution of personality and pain related beliefs: Coping strategies in adjustment to chronic pain. Dissertation Abstract International Section B: The Sciences and Engineering, 58, 1586.

[2]. Ashton, H., Ebenezer, J.F. \& Golding, J.W. (1984). Effects of acupuncture and transcutaneous electrical nerve stimulation on coldinduced pain in normal subjects. Journal of Psychosomatic Research. 28:301-308

[3]. Bond M.R., Glynn, J.P. \& Thomas, D.G. (1976). Relation between pain and personality in patients receiving pentazocine (Fortral) after surgery. Journal of Psychosomatic Research; 20:369-81.

[4]. Brown, R.A., Fader, K. \& Barber, T.X. (1973). Responsiveness to pain: stimulus specificity versus generulity. Psychological Record, 3;23:1-7.

[5]. Buhler, K. E. \& Land, T. (2003). Burnout and personality in intensive care: An empirical study. Hospital Topics. Research and Perspectives on Health Care, 81, 5-12.

[6]. Cavanaugh, S.V. (1983). The prevalence of emotional and cognitive dysfunction characteristics as differential variables of the pain experience. Journal Behavioral Medicine, 27, 147-165.

[7]. Davidson, P.O. \& McDougall, E,A. (1969). Personality and pain tolerance measures. Perceptual Motor Skills 28:787-790.

[8]. Deary, I. J., Blenkin, H., Agius, R.M., Endler, N. S., Zealley, H., \& Wood, R. (1996). Models of job-related stress and personal achievement among consultant doctors. British Journal of Psychology, 87, 3-29.

[9]. Deary, I. J.,Watson, R., \& Hogston, R. (2003). A longitudinal cohort study of burnout and attrition in nursing students. Journal of Advanced Nursing, 43, 71-81.

[10]. Ensel, W.M. (1986). Sex, marital status, and depression: the role of life events and social support. In: Lin, N., Denn, A. \& Ensel, W.H. (eds). Social support, life events, and depression. New York (NY): Academic Press.

[11]. Fillingim, R.B. (2000). Sex, gender and pain: a biopsychosocial framework. In: Fillingim, R.B. (ed). Sex, gender and pain. Seattle: IASP press.

[12]. Howard, L.F. (2007) Pain Perception: The Dana Guide to Britain Health; A practical family Reference from Medical Experts.

[13]. LePine, J. A., LePine, M. \& Jackson, C. L. (2004). Challenge and hindrance stress: Relationships with exhaustion, motivation to learn, and learning performance. Journal of Applied Psychology, 89, 883-891.

[14]. Leresche, I. (1998). Chronic pain. In: Blechman, E.A. \& Brownell, K.D. (eds). Behavioral medicine and women. New york: The Guilford press.

[15]. Levine, P.M., Tursky, B. \& Nichols, D.C. (1966). Tolerance for pain, extraversion and neuroticism: Failure to replicate results, Perceptual Motor Skills 23:847-850.

[16]. Lynn, R. \& Eysenck, H.J. (1961). Tolerance for pain, extraversion and neuroticism. Perceptual Motor Skills 12:161-162.

[17]. Martin, J.E \& Inglis, J. (1965). Pain tolerance and narcotic addiction. British Journal of Social \& Clinical Psychology; 4:224-9.

[18]. McCrae, R.R. \& Costa, P.T. (1986). Personality, coping, and coping effectiveness in an adult sample. Journal of Personality, 54, 385-405. 
[19]. Meana, M. \& Stewart, D. (2000). Pain: adding to the affective burden. In: Steiner, M., Yonkers, K.A. \& Ericsson, E. (eds). Mood disorders in women. London: Martin Dunitz.

[20]. Merskey, H. \& Bogduk, N. (1994). Classification of chronic pain. 2nd ed. Seattle: IASP press.

[21]. Morasso, P., Costantini, M., Baracco, G., Borreani, C. \& Capelli, M. (1996).

[22]. Assessing psychological distress in cancer patients: Validation of a self-administered questionnaire. Oncology, 53,295-302

[23]. Murrell, S.A., Himmelfarb, S. \& Wright, K. (1983). Prevalence of depression and its correlated in older adults. American Journal of Epidemiology; 117:173-85.

[24]. Piedmont, R. L. (1993). A longitudinal analysis of burnout in the health care setting: The role of personal dispositions. Journal of Personality Assessment, 61, 457-473.

[25]. Ramírez-Maestre, C., López, A.E., \& Esteve, M. R. (2004). Personality characteristics as differential variables of the pain experience. Journal Behavioural Medicine, 27, 147-165

[26]. Schalling, D. (1971). Tolerance for experimentally induced pain as related to personality. Scowl. Journal of Psychology, 12:271281 .

[27]. Sternberg, R.J. (2004). Psychology. (4 ${ }^{\text {th }}$ ed.) Belmont: Thomson/Wadsworth

[28]. Taenzer, P., Melzack, R. \& Jeans, M.E. (1986). Influence of psychological factors on post-operative pain, mood and analgesic requirements. Pain; 24:331-42.

[29]. Turk, D.C., Okifuji, A. \& Scharff, L. (1995). Chronic pain and depression-role of perceived impact and perceived control in different age cohorts. Pain; 61: 93-101

[30]. Verbrugge, L.M. (1985). Gender and health: an update on hypotheses and evidence

[31]. Zellars, K. L., Perrewe, P. L. \& Hochwarter, W. A. (2000). Burnout in health care: The role of the five factors of personality. Journal of Applied Social Psychology, 30(8), 1570-1598. 